\title{
Beyond Zoonoses in One Health: Non-communicable Diseases Across the Animal Kingdom
}

\author{
B. Natterson-Horowitz ${ }^{1,2 * t}$, Marion Desmarchelier ${ }^{3+}$, Andrea Sylvia Winkler ${ }^{4,5 t}$ and \\ Hélène Carabin ${ }^{6,7,8,9+}$
}

${ }^{1}$ Division of Cardiology, David Geffen School of Medicine at University of California, Los Angeles (UCLA), Los Angeles, CA, United States, ${ }^{2}$ Department of Human Evolutionary Biology, Harvard University, Boston, MA, United States, ${ }^{3}$ Department of Clinical Sciences, Faculté de Médecine Vétérinaire, Université de Montréal, Saint-Hyacinthe, QC, Canada, ${ }^{4}$ Department of Neurology, Center for Global Health, Technical University of Munich, Munich, Germany, ${ }^{5}$ Centre for Global Health, Institute of Health and Society, University of Oslo, Oslo, Norway, ${ }^{6}$ Department of Pathology and Microbiology, Faculté de Médecine Vétérinaire, Université de Montréal, Saint-Hyacinthe, QC, Canada, ${ }^{7}$ Department of Social and Preventive Medicine, École de Santé Publique (ESPUM), Université de Montréal, Montréal, QC, Canada, ${ }^{8}$ Groupe de Recherche en Épidémiologie des Zoonoses et Santé Publique (GREZOSP), Saint-Hyacinthe, QC, Canada, ${ }^{9}$ Centre de Recherche en Santé Publique (CReSP), Montréal, QC, Canada

OPEN ACCESS

Edited by:

Pierre Echaubard,

SOAS University of London,

United Kingdom

Reviewed by:

Alice Vismarra,

University of Parma, Italy

${ }^{*}$ Correspondence:

B. Natterson-Horowitz natterson-horowitz@fas.harvard.edu

tORCID:

B. Natterson-Horowitz orcid.org/0000-0002-6145-9689

Marion Desmarchelier orcid.org/0000-0001-6931-7936

Andrea Sylvia Winkler orcid.org/0000-0003-3131-6983

Hélène Carabin orcid.org/0000-0002-2822-4730

Specialty section:

This article was submitted to

Planetary Health

a section of the journal

Frontiers in Public Health

Received: 01 November 2021 Accepted: 30 December 2021

Published: 26 January 2022

Citation:

Natterson-Horowitz B, Desmarchelier M, Winkler AS and Carabin H (2022) Beyond Zoonoses in

One Health: Non-communicable Diseases Across the Animal Kingdom.

Front. Public Health 9:807186.

doi: 10.3389/fpubh.2021.807186
Keywords: non-communicable disease (NCD), one health, public health, environmental exposure, animal surveillance

\section{INTRODUCTION}

Greater than $70 \%$ of all human deaths are due to non-communicable diseases (NCDs) (1). Increasingly environmental exposures, from air pollution, second-hand smoke, heavy metals, phthalates, pesticides, and endocrine disrupting chemicals, have been linked to a range of NCDs including many cancers, cardiopulmonary diseases, congenital abnormalities and other pathologies (2). Many of the same environmental effects that elevate disease risk in humans, also do so in other species. In fact, the smaller size of many non-human animals, shorter lifespans and their greater exposure to environmental hazards may accelerate the natural history of pathology (2). Between domestication, urbanization and increased land use, the line demarcating "human" and "animal" environments is increasingly blurred and health professionals have an opportunity to turn to animal models to address human health. For instance, surveillance for NCDs in other species has the potential to alert human health professionals to environmental hazards before the emergence of pathology in human populations (2). The importance of animal sentinels in detecting and combating communicable diseases has been made strikingly clear over the past decades (3) as well as by the recent COVID-19 pandemic. The high percentage of communicable diseases with zoonotic origins reveals the need for broad surveillance of wild and domestic animal populations that may carry pathogens that can infect in humans (4). However, despite increased awareness of and resources for surveillance of animal sentinels with zoonotic diseases, far fewer resources have been directed toward surveillance of animal populations for NCDs (5) and widespread reforms addressing the connection between human, animal and environmental health remain elusive. Here, we briefly present examples of NCDs in non-human animals that derive from shared environmental sources to emphasize the utility and need for species-spanning NCD surveillance (Figure 1).

\section{NCDS, ENVIRONMENTS, AND THREATS}

Animal sentinels can provide critical information on a number of high impact human NCDs including cancers, developmental abnormalities and neuropsychiatric disorders. For example, companion animals exposed to second-hand smoke are at increased risk for lung cancer and household chemicals cause bladder and other cancers in both dogs and humans living in the same 


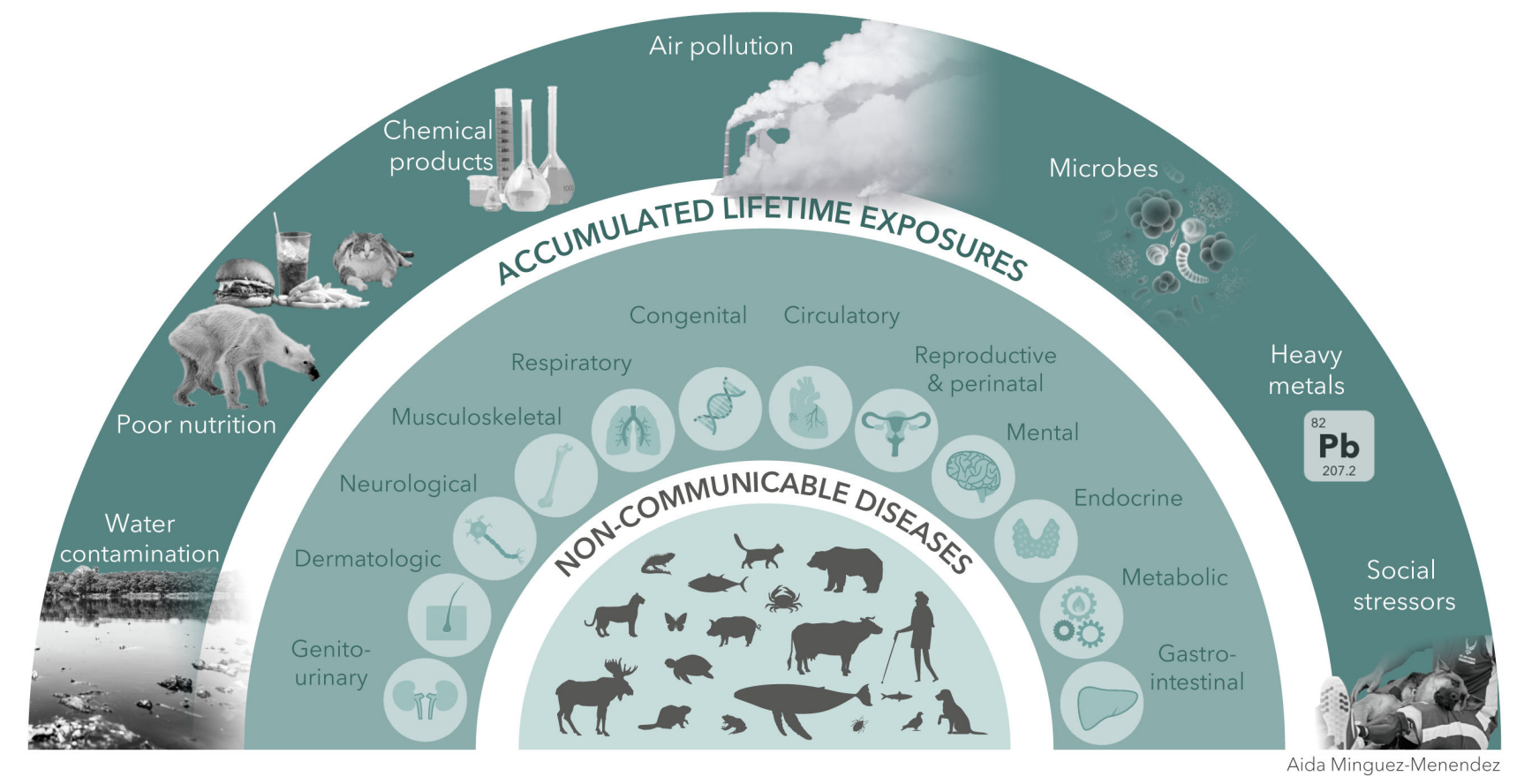

FIGURE 1 | Shared environmental exposures contribute to NCDs across species.

households (6). Strong evidence now links various carcinomas to polycyclic aromatic hydrocarbons $(\mathrm{PAH})$, persistent organohalogen compounds (POCs) and other endocrine disrupting agents in free-living marine mammals, rodents, and some bird species (7-9). Due to their heightened sensitivity, ferrets and birds have also been efficient sentinels for airborne toxic particles $(10,11)$, which can lead to lung cancer. Surveillance of animal populations can provide human health professionals with early warnings of environmental carcinogens.

Environmental factors, especially exposure to fine particulate matter, have been implicated in over $25 \%$ of ischemic heart disease related deaths (12). Atherosclerosis has been identified in the vasculature of a wide range of animals in wild, captive, companion and agricultural settings great apes (13), parrots (14, 15), domestic cats (16), swine, and horses (17). The vulnerability of other animals to atherosclerosis and the increasingly strong linkage between environmental factors and atherogenesis point to a major underleveraged source of insights. Surveillance of animal populations for atheroma may expose heightened presence of atherogenic environmental exposures, such as particulate matter.

A growing list of environmental contaminants are now recognized to increase risk of congenital syndromes in humans (18). These include: plastic and related chemicals that delay fetal brain development, endocrine disrupting chemicals and altered sex skew, genitourinary abnormalities, and a host of other disorders. Such endocrine disruptors are found in a wide range of everyday products, including cosmetics, toys, plastic containers and food (19). In the wild, environmental contaminants contribute to declining numbers of bees due to neonicotinoid-induced impaired social behavior (20), amphibians going through mass extinction due to multiple environmental disturbances (21), and feminized male freshwater fish due to endocrine disrupting compounds (22), which all have direct relevance to human health. Surveillance for congenital disorders in animals may expose otherwise undetected links between environmental toxins and congenital abnormalities in humans.

In humans, NCDs are associated with social determinants of health and have been linked to social and environmental factors such as poverty, gender, race, food insecurity or being exposed to violence $(1,23-25)$. Lifestyles contribute to NCDs in both animals and humans. For example, diet and inactivity which are linked to cardiovascular disease in humans are also believed to increase risk in captive and companion birds (14). Obesity--and its associated comorbidities--has also been linked to diet and levels of activity in humans, cats, dogs, and other species (2628). In some cases, the human-animal bond can be leveraged to motivate lifestyle behavioral changes with positive health effects (29).

The presence of an abusive individual in a household has been shown to increase the risk faced by all individuals, regardless of species-type, living with the abuser $(2,11,30-32)$. While the effects on domestic animals have not been rigorously studied, a history of abuse, neglect, or prior mismanagement is reported as a major co-occurrent factor in human dog bite-related fatalities (30). Developmental vulnerability to early trauma has been linked to increased risk of mental illness in later life in humans $(33,34)$ and a growing body of research supports similar relationships in dogs $(32,35)$. Since animal abuse often precedes abuse of humans, it has been suggested that pets can be sentinels for potential violence in human homes and this connection points 
to a novel approach to reducing risk of trauma and subsequent psychopathology in humans.

Mental illness affects $15-20 \%$ of humans $(32,33)$ and environmental factors are increasingly implicated in a wide range of neuropsychiatric disorders. As estimates of humans affected by mental illness rise, the relevance of neuropsychiatric health of other species has increasing relevance to human mental health. In Minamata, Japan, for example a mysterious neuropsychiatric disorder in humans was not identified as methylmercury poisoning until cats in the area began behaving aberrantly (36). Canine and feline anxiety and compulsive disorders share features with human correlates (37) and featherdamaging behavior in parrots is a model for trichotillomania (38, 39). Unfortunately, there has been limited knowledge exchange between human psychiatry and veterinary behavioral medicine, which was only recognized as a specialty of veterinary medicine in 1993. Investigating common processes of brain dysfunction and their management strategies across species, such as post-traumatic stress disorder (PTSD) in military canines and humans, might be valuable in the fight against mental illness stigma, which is recognized as an important barrier to care. This has particular salience for health professionals, who have higher rates of depression than the general public, with veterinarians suffering the highest rate of suicide of all (40).

\section{DISCUSSION}

In 1999, the Bronx Zoo's veterinary pathologist had concerns that a parallel epidemic of encephalitis among elderly people might be related to her recent avian die off. Her efforts to engage the CDC and the New York State Health department in an investigation were at first met with resistance, thus delaying the identification of West Nile Virus as the common pathogen. Since that time, some progress has been made with the creation of a few joint surveillance systems for infectious agents and antimicrobial resistance. However, perhaps as a consequence of a long tradition of human exceptionalism in medicine, many physicians still lack awareness of the connection between NCDs in humans and other species. In fact, traditional medical education has a poor record of teaching the similarities between human and animal health and has largely ignored the connection between human and wildlife health (41). As NCDs continue to surge in human communities and as the connection between these diseases and the environment grows more clear, the health of animals sharing these vulnerabilities is of great importance.

While strengthened evidence for the role of environments in NCD-related human deaths has generated appropriate concern

\section{REFERENCES}

1. WHO. Non Communicable Diseases. World Health Organ. (2021). Available online at: https://www.who.int/news-room/factsheets/detail/noncommunicable-diseases (accessed October 5, 2021). among human health professionals, the low level of resources directed at surveillance efforts indicates that the importance of animal sentinels appears to be not well-understood. In a recently published systematic review of animal surveillance, most studies focused on zoonotic and infectious pathologies rather than NCDs (5). Additionally, numerous barriers were identified which limit effective surveillance efforts including problems with data standardization, collection and sharing, poor integration of effort across disciplines, and under engagement by private sector stakeholders. As a consequence, the authors report "the systems cannot meet their objective, such as the detection of health events in animals to prevent human cases or the attribution of sources for human cases" remains underdeveloped (5).

While the lessons of West Nile and other zoonotic diseases helped increase collaboration across the fields of human and veterinary medicine, it is time to apply these lessons from zoonoses to non-communicable health challenges threatening humans, animals and their shared environments around the globe. The opportunity is tremendous, yet it remains unrealized. Employing One Health frameworks can provide innovative solutions to prevent and treat NCDs across the animal kingdom. Increased awareness among human health professionals and stakeholders of the shared vulnerability across species of environmentally- linked NCDs should ignite interest and ideally mobilize resources for NCD surveillance across species (42). These efforts could not only improve the health of humans, but of all species sharing exposures in increasingly hazardous environments.

\section{AUTHOR CONTRIBUTIONS}

BN-H consolidated the final version of the manuscript. All authors contributed to idea conception, draft manuscript preparation, reviewed the results, and approved the final version of the manuscript.

\section{FUNDING}

HC was supported in part by the Canada Research Chair in Epidemiology and One Health (Grant no. CRC 950-231857).

\section{ACKNOWLEDGMENTS}

The authors wish to acknowledge Dr. Aida Minguez-Menendez at Université de Montréal for her creativity, talent and assistance with designing Figure 1. The authors also acknowledge Kerstin Langenberger (www.arctic-dreams.com) who gave us permission to use the photograph of the polar bear. 
4. Judson SD, Rabinowitz PM. Zoonoses and global epidemics. Curr Opin Infect Dis. (2021) 34:385-92. doi: 10.1097/QCO.0000000000000749

5. Bordier M, Uea-Anuwong T, Binot A, Hendrikx P, Goutard FL. Characteristics of one health surveillance systems: a systematic literature review. Prev Vet Med. (2020) 181:104560. doi: 10.1016/j.prevetmed.2018.10.005

6. Garden OA, Volk SW, Mason NJ, Perry JA. Companion animals in comparative oncology: One Medicine in action. Vet J. (2018) 240:613. doi: 10.1016/j.tvjl.2018.08.008

7. Bossart GD. Marine mammals as sentinel species for oceans and human health. Vet Pathol. (2011) 48:676-90. doi: 10.1177/0300985810388525

8. Pesavento PA, Agnew D, Keel MK, Woolard KD. Cancer in wildlife: patterns of emergence. Nat Rev Cancer. (2018) 18:646-61. doi: 10.1038/s41568-018-0045-0

9. García-Fernández AJ, Espín S, Gómez-Ramírez P, Martínez-López E, Navas I. Wildlife sentinels for human and environmental health hazards in ecotoxicological risk assessment. In: Roy K, editor. Ecotoxicological QSARs: Methods in Pharmacology and Toxicology. New York, NY: Humana (2020). doi: 10.1007/978-1-0716-0150-1_4

10. Rasmussen RE, Mannix RC, Oldham MJ, Phalen RF. Effects of nitrogen dioxide on respiratory tract clearance in the ferret. $J$ Toxicol Environ Health Part Curr Issues. (1994) 41:109-20. doi: 10.1080/15287399409531830

11. Neo JPS, Tan BH. The use of animals as a surveillance tool for monitoring environmental health hazards, human health hazards and bioterrorism. Vet Microbiol. (2017) 203:40-48. doi: 10.1016/j.vetmic.2017.02.007

12. Franklin BA, Brook R, Arden Pope C. Air pollution and cardiovascular disease. Curr Probl Cardiol. (2015) 40:20738. doi: 10.1016/j.cpcardiol.2015.01.003

13. Horowitz BN, Kutinsky IB, Linde A. Species-spanning echocardiography: cardiovascular insights from across the animal kingdom. Curr Cardiol Rep. (2020) 22:165. doi: 10.1007/s11886-020-01417-8

14. Beaufrère $H$, Ammersbach $M$, Reavill $D R$, Garner MM, Heatley JJ, Wakamatsu N, et al. Prevalence of and risk factors associated with atherosclerosis in psittacine birds. J Am Vet Med Assoc. (2013) 242:1696704. doi: 10.2460/javma.242.12.1696

15. Beaufrère H, Nevarez JG, Holder K, Pariaut R, Tully TN, Wakamatsu N. Characterization and classification of psittacine atherosclerotic lesions by histopathology, digital image analysis, transmission and scanning electron microscopy. Avian Pathol. (2011) 40:531-44. doi: 10.1080/03079457.2011.607427

16. Karkamo V, Airas N, Lindén J, Hagner K, Mäyränpää MI, Kovanen PT, et al. Severe spontaneous atherosclerosis in two korat breed cats is comparable to human atherosclerosis. J Comp Pathol. (2021) 188:5261. doi: $10.1016 /$ j.jcpa.2021.08.006

17. Stöllberger C, Markovic M. Failure in cardiac action: comparing humans, dogs, cats, and horses. In: Jensen-Jarolim E, editor. Comparative Medicine. Vienna: Springer (2017). doi: 10.1007/978-3-319-47007-8_1

18. Nelson W, Wang Y-X, Sakwari G, Ding Y-B. Review of the effects of perinatal exposure to endocrine-disrupting chemicals in animals and humans. Rev Environ Contam Toxicol Vol 251. (2019) 2019:13184. doi: 10.1007/398_2019_30

19. Dodson RE, Nishioka M, Standley LJ, Perovich LJ, Brody JG, Rudel RA. Endocrine disruptors and asthma-associated chemicals in consumer products. Environ Health Perspect. (2012) 120:935-43. doi: 10.1289/ehp.1104052

20. Raine NE. Pesticide affects social behavior of bees. Science. (2018) 362:6434. doi: 10.1126/science.aav5273

21. Wake DB, Vredenburg VT. Are we in the midst of the sixth mass extinction? A view from the world of amphibians. Proc Natl Acad Sci USA. (2008) 105:11466-73. doi: 10.1073/pnas.0801921105

22. Tyler CR, Filby AL. Feminized fish, environmental estrogens, wastewater effluents in english rivers. In: Elliott JE, Bishop CA, Morrissey CA, editors. Wildlife Ecotoxicology: Forensic Approaches Emerging Topics in Ecotoxicology. New York, NY: Springer (2008). doi: 10.1007/978-0-387-89432-4_13

23. Branca F, Lartey A, Oenema S, Aguayo V, Stordalen GA, Richardson R, et al. Transforming the food system to fight non-communicable diseases. $B M J$. (2019) 364:1296. doi: 10.1136/bmj.1296

24. Marmot M, Bell R. Social determinants and non-communicable diseases: time for integrated action. BMJ. (2019) 364:1251. doi: 10.1136/bmj.1251
25. Garry S, Checchi F. Armed conflict and public health: into the 21st century. $J$ Public Health. (2020) 42:e287-98. doi: 10.1093/pubmed/fdz095

26. Bartges J, Kushner RF, Michel KE, Sallis R, Day MJ. One health solutions to obesity in people and their pets. J Comp Pathol. (2017) 156:32633. doi: 10.1016/j.jcpa.2017.03.008

27. Bjørnvad C. Lifestyle and diabetes mellitus in cats and dogs. Acta Vet Scand. (2015) 57:K4. doi: 10.1186/1751-0147-57-S1-K4

28. German AJ, Ryan VH, German AC, Wood IS, Trayhurn P. Obesity, its associated disorders and the role of inflammatory adipokines in companion animals. Vet J. (2010) 185:4-9. doi: 10.1016/j.tvjl.2010.04.004

29. Feil C, Staib F, Berger MR, Stein T, Schmidtmann I, Forster A, et al. Sniffer dogs can identify lung cancer patients from breath and urine samples. $B M C$ Cancer. (2021) 21:917. doi: 10.1186/s12885-021-08651-5

30. Patronek GJ, Sacks JJ, Delise KM, Cleary DV, Marder AR. Co-occurrence of potentially preventable factors in $256 \mathrm{dog}$ bite-related fatalities in the United States (2000-2009). J Am Vet Med Assoc. (2013) 243:1726-36. doi: 10.2460/javma.243.12. 1726

31. Febres J, Brasfield H, Shorey RC, Elmquist J, Ninnemann A, Schonbrun YC, et al. Adulthood animal abuse among men arrested for domestic violence. Violence Women. (2014) 20:1059-77. doi: 10.1177/107780121454 9641

32. McMillan FD. Behavioral and psychological outcomes for dogs sold as puppies through pet stores and/or born in commercial breeding establishments: Current knowledge and putative causes. J Vet Behav. (2017) 19:14-26. doi: 10.1016/j.jveb.2017.0 1.001

33. Guintivano J, Kaminsky ZA. Role of epigenetic factors in the development of mental illness throughout life. Neurosci Res. (2016) 102:56-66. doi: 10.1016/j.neures.2014.0 8.003

34. Agorastos A, Pervanidou P, Chrousos GP, Kolaitis G. Early life stress and trauma: developmental neuroendocrine aspects of prolonged stress system dysregulation. Hormones. (2018) 17:507-20. doi: 10.1007/s42000-018-0 065-x

35. Dietz L, Arnold A-MK, Goerlich-Jansson VC, Vinke CM. The importance of early life experiences for the development of behavioural disorders in domestic dogs. Behaviour. (2018) 155:83-114. doi: 10.1163/1568539X-0000 3486

36. Tsuda T, Yorifuji T. The History of Minamata Disease and Public Health Policy : Epidemiology. in Methylmercury, Minamata and Modern Menaces. Seoul: Epidemiology (2020). doi: 10.1097/01.ede.0000391971.19 081.05

37. Luescher AU. Diagnosis and management of compulsive disorders in dogs and cats. Vet Clin Small Anim Pract. (2003) 33:253-67. doi: 10.1016/S0195-5616(02)00100-6

38. Mellor E, Brilot B, Collins S. Abnormal repetitive behaviours in captive birds: a Tinbergian review. Appl Anim Behav Sci. (2018) 198:10920. doi: 10.1016/j.applanim.2017.09.011

39. van Zeeland YRA, Spruit BM, Rodenburg TB, Riedstra B, van Hierden YM, Buitenhuis B, et al. Feather damaging behaviour in parrots: A review with consideration of comparative aspects. Appl Anim Behav Sci. (2009) 121:75-95. doi: 10.1016/j.applanim.2009.0 9.006

40. Fink-Miller EL, Nestler LM. Suicide in physicians and veterinarians: risk factors and theories. Curr Opin Psychol. (2018) 22:23-6. doi: 10.1016/j.copsyc.2017. 07.019

41. Rabinowitz PM, Natterson-Horowitz BJ, Kahn LH, Kock R, Pappaioanou M. Incorporating one health into medical education. BMC Med Educ. (2017) 17:45. doi: 10.1186/s12909-017-0 883-6

42. Bordier M, Uea-Anuwong T, Sicard JC, Hendrikx P, Goutard FL. How to apply a one health approach to surveillance: A systematic literature review. In: Brennan ML, Lindberg A, editors. Proceedings of the Society for Veterinary Epidemiology and Preventive Medicine Annual Meeting (Tallinn). (2018). p. 184-96. 
Conflict of Interest: The authors declare that the research was conducted in the absence of any commercial or financial relationships that could be construed as a potential conflict of interest.

Publisher's Note: All claims expressed in this article are solely those of the authors and do not necessarily represent those of their affiliated organizations, or those of the publisher, the editors and the reviewers. Any product that may be evaluated in this article, or claim that may be made by its manufacturer, is not guaranteed or endorsed by the publisher.

Copyright (c) 2022 Natterson-Horowitz, Desmarchelier, Winkler and Carabin. This is an open-access article distributed under the terms of the Creative Commons Attribution License (CC BY). The use, distribution or reproduction in other forums is permitted, provided the original author(s) and the copyright owner(s) are credited and that the original publication in this journal is cited, in accordance with accepted academic practice. No use, distribution or reproduction is permitted which does not comply with these terms. 